\title{
Architecture for a Creative Information System
}

\author{
Henrique São Mamede ${ }^{1}$ and Vitor Santos ${ }^{2}$ \\ ${ }^{1}$ Universidade Aberta, Rua da Escola Politécnica, no 141-147, 1269-001 Lisboa, Portugal \\ ${ }^{2}$ Microsoft, Edifício Qualidade, C1-C2, Av. Prof. Doutor Aníbal Cavaco Silva, Tagus Park
}

\begin{abstract}
Considering that the capacity to innovate is increasingly becoming a decisive factor in the competition between organisations, the study and conception of systems that help the birth of new ideas, products and solutions is rising in importance. In this article, the authors consider the concept of Creative Information Systems and present a proposal for the development of architecture for such a system based on the creative technique of brute thinking.
\end{abstract}

Keywords: Information Systems, Creative Thinking, Innovation.

\section{Introduction}

There are many definitions of creativity presented by various schools of thought. As an example, and coming from distinct environments, we can consider two different approaches presented by John Kao and Stan Gryskiewicz (Kao 1996, Gryskiewicz 1993). The first defines creativity as the process through which ideas are generated, developed and transformed into value. The second defines creativity as a useful novelty.

For the context of the present article, we will define creativity as the ability to imagine, invent and create new solutions, unexpected, original, useful, and capable of solving problems of unknown forms or to present things that where never thought of before. Creativity is the result of an intentional thought, with the aim of finding new solutions to problems or to guarantee already known solutions (Adams 1986). All human beings have the potential to be creative, some more than others, and everyone can develop and improve their creative capacity.

There is a great diversity of techniques that support creative thinking and a large array of tools which perform some of those techniques ${ }^{1}$. All the creativity techniques have strong and weak points and can be more or less useful depending on the kind of problem (Jay 2000).

Considering that the capacity to innovate is becoming more and more a decisive factor in enterprise competition and in everyday life, the study and conception of systems that help to innovate have an increasing importance (Bennetti 1999).

\footnotetext{
${ }^{1}$ Creative techniques list, http://www.mycoted.com/creativity/techniques/ Creative thinking techniques and lateral thinking, http://www.brainstorming.co.uk/tutorials/creativethinkingcontents.html Creative thinking techniques, http://members.optusnet.com.au/ charles57/Creative/Techniques
} 
In this context, the hypothesis which would appeal to the capacity of computer systems, based on knowledge or on adaptations of creativity techniques in order to help to produce new combinations and to give unexpected, original, useful and satisfactory answers, focused in one specific context, is something extremely challenging. In this article, we consider the concept of "Creative Information System" which introduces us to a proposal of a concrete architecture based on the technique of creativity named brute thinking (Michalko 1991). This technique is a powerful lateralthinking technique that is very easy to use. It is by far the simplest of all creative techniques and is now widely used by people who need to create new ideas ${ }^{2}$.

\section{About Creative Thinking}

While enquiring into creativity, we come across a variety of theories and models that explain the creative thought and its mental procedures (Koestler 1964). The most well known theory is the concept of the divergent thought by the American J. P. Guilford (Gardner 1998, Arieti 1993), a decisive theory in the inquiry of creativity in the United States between the 1960s and 1970s, and the theory of the lateral thought, developed by Edward De Bono (Binnig 1997, Baxter 2000) between the 1970s and 1980s.

Later on, in a conference about 'Design Thinking', Nigel Cross criticized those creators, stating that frequently, they have difficulties in departing from an initial idea and to choose a new path for the search of a new solution (Binnig 1997), bringing into attention the necessity for a wider use of lateral thought in creativity.

Other aspects of scant consideration by Guilford and De Bono are the personal characteristics and the cognitive styles of an individual, the bio-social conditions (work structures, communication styles, conflict management, hierarchies) and environments (colors and shapes in-house, temperature, light, noise, etc.) where individuals work. All these aspects had already been identified by one of the most recent theories that explain creativity - the Theory of the Systems (Cardoso de Sousa 1998).

The systemic vision of creativity is based on the General Theory of the Systems, from the biologist Ludwig von Bertalaffy, who applied this term in the 1970s to frequently describe points of the biological, physical and social systems. Previously, systemic theories had been developed within the cybernetics (Wiener 1950), where the objectives were to dominate the complexity of technical and economic systems (Bono 1994). On the base of the von Bertalaffy and Wiener's work, a theory of systems was largely developed and it leads us to the explanation, simulation and manipulation of the Nature process evolution. Currently, the main goal is to find a universal theory on the common systemic principles to different sciences (Jonas 1994).

The majority of the investigators in the creativity field agree with the three main features that characterize a creative person: the fluidity, the flexibility and the originality of the thought. These three pointers are the criteria of evaluation in many tests of creativity (Cross et al. 1992). The fluidity of thought points out the ease of producing ideas in quantity within a limited time frame. This is about a non critical

\footnotetext{
${ }^{2}$ Edward de Bono, http://www.edwarddebono.com/PassageDetail.php?passage_id=692\&
} 
thought which can be stimulated by techniques such as brainstorming or brainwriting (Guilford 1986).

The flexibility of the thought is characterized by ease not only of producing ideas in quantity, but also in quality and to find answers that allow different classifications. As opposed to flexibility there is rigidity, immobility and incapability to change attitudes, behaviors or points of view, the impossibility to offer other alternatives or to change an already applied method. When a proposal is created, if it is different from the existing ones, within a certain context, because it is uncommon or unusual, then it is considered originality of thought.

The analytical thought is the process to recognize, classify and describe the elements of a problem. Humans describe themselves to others and to the world as analytical beings, able to study and decompose everything in parts. The conclusions of the analysis can give us tracks to the accomplishment of a hypothesis, an analogy or a new synthesis. As the traditions of the western thought are based on analysis and logical reasoning, analysis is being increasingly used as one of the abilities of creative thought; however, it is known that many students have difficulties to accomplish functional and morphological analyses problems (Ferreras 1999).

The accomplishment of hypotheses is another procedure of the creative thought. It is the ability to assume and to establish. In the experimental sciences, a reasonable explanation of the facts is provisionally adopted with the aim to submit it to a methodical verification for the experience. It is the search of causes and consequences. An important procedure of the hypothetical thought is the divergent interrogation. Divergent questions allow some valid answers. These are inducing because they are open, thus stimulating a diversity of ideas, images, feelings and immediate reactions.

In order to understand relations and interconnections, it is necessary to compare and relate. Another elementary operation to solve a problem in a creative way is the analogical-comparative thought. It is about a mental process of bi-association of ideas (Smith 1990) which allows establishing a new and uncommon relation between objects and situations. The ideas are bi-associations; to create is to recombine the available knowledge. The development of the analogical thought demands imagination training and the use of metaphors.

The synthetic thought is a combinational thought that carries through a new synthesis in an individual or group base. It is the dispersed integration of fragmentary elements and information in a new combination (Gogatz and Mondejar 2005). To create an innovative product through an original synthesis, it is necessary to have an open attitude to different stimulations in order to have the maximum possible choice. Finally, but just as important, the mental procedure to process creation is intuition. It is linked with the direct and immediate contemplation of the reality or a problem for which a different solution from the one that could be obtained by a logical reasoning is being sought. It is an unconscious thought, where the procedure is not explainable. According to the physicist Gerd Binnig, intuition is a kind of analysis or synthesis that is not processed logically when the problem is too complex (Smith 1990). Thus, the intuitive thought helps the designer to take a decision if the situation is not well defined and unclear and data is contradictory, incomplete or too subjective, which occurs with the majority of situations concerning design projects. 


\section{The Creative Information System}

\subsection{Creativity Techniques}

To the creativity process, one or more available techniques are referred for the desired effect. Overall there are hundreds of techniques published in the works of Michael Michalko (Michalko 2000), Van Gundy (Van Gundy, 2007), James Higgins (Higgins, 1996), Dilip Mukerjea (Mukerjea, 2003) among other authors. These techniques are tools able to suit different approaches for different creative parties. For example, techniques for the definition of existing problems, to explore attributes of a problem, to generate alternatives, for visual explorations, metaphors, analogies and evaluation and implementation of ideas. A few groups of techniques will be presented in the following text as a small example. In this sense, we have the technique of random word or image, false rules, random website, the SCAMPER, research and the reusing, role-play, escaped and analogies.

The random word technique, also called brute thinking, refers to the random generation of a word that will work as an initial stimulation, extracting its underlying principles and applying them to the problem. The technique of the random image is by all means similar to the previous one, except its resource, which is an image instead of a word. The technique of false rules applies rules that previously were not considered possible to the problems, hence the name "false". Making the false rule and forcing its use in the new situation, forces it in differentiated directions, which normally would not be followed.

The random website technique consists of finding and consulting sites randomly, collecting ideas and using those ideas to generate new ideas. The SCAMPER technique is a good example of a elaborate technique that uses a set of directed questions that you answer about your problem in order to come up with new ideas. The stimulus comes from forcing yourself to answer those questions which you would not normally pose. The questions direct you to thinking about a problem in ways which typically throw up new ideas.

The role play technique involves changing the perspective of the problem, acting like another person and trying to determine the way he would face the question.

The escaped technique consists in generating the wildest proposals without possible limits, without any moral, rules, labels, laws or standards.

The technique of analogies refers to the use of an analogy or a metaphor in a particular situation in order to locate similar opportunities or solutions in other areas.

More information and hyperlinks for related web pages with techniques of creative thought can be found in the website of Andy Beckett ${ }^{3}$ who is promoting a body of work of compilation of various techniques ${ }^{4}$. We also appreciate the recent work of Hudson (Hudson 2007).

\subsection{Definition of "Creative Information System"}

We define "Creative Information System" (CIS) as an information system that, facing a concrete problem in a certain context and using an adjusted creativity technique, is

\footnotetext{
${ }^{3}$ http://members.optusnet.com.au/ charles57/Creative/Techniques/

${ }^{4}$ http://www.mycoted.com/creativity/techniques/
} 
able to generate automatically a potentially innovative set of answers for the solution of a problem (Santos and Mamede 2007).

The information system that we consider, does not cover all the development cycle of the creative process, but allows relying on the computer system in terms of all the direct creativity techniques application, with a larger or smaller sophistication degree, as shown in fig. 1 (Santos and Mamede 2006).

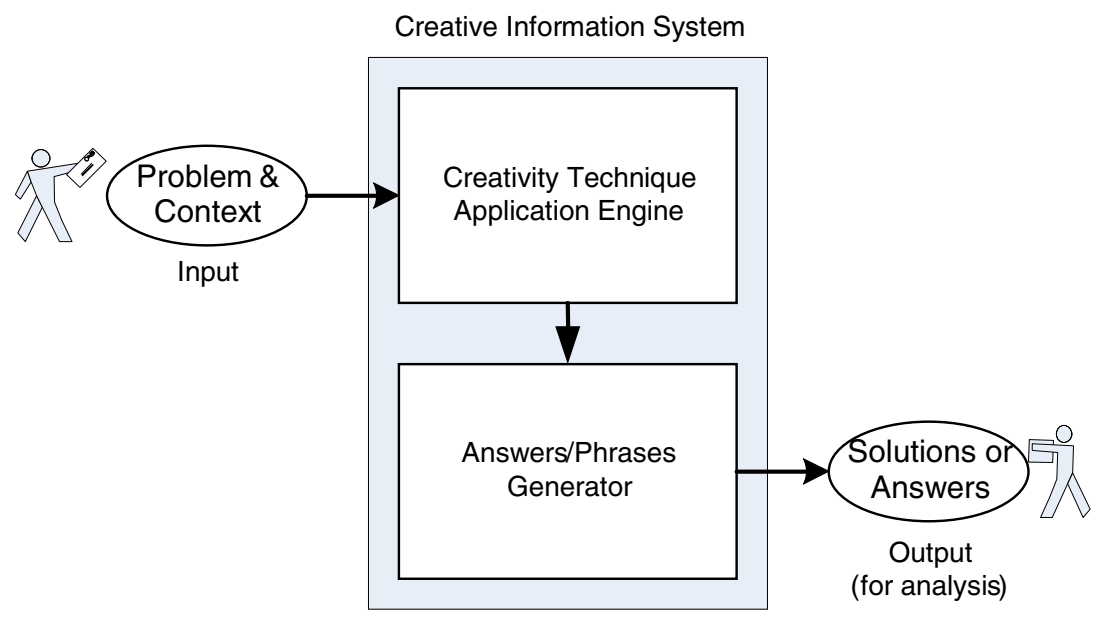

Fig. 1. General scheme of a Creative Information System

To be able to work, the information system has to receive the necessary minimum inputs as a starting point, namely the specification of the problem, the context and the restrictions to the generated solutions. The answers are generated through the application of one or more techniques of creativity or by the combination of those adapted in order to be implemented through computer applications, with a larger or smaller degree of sophistication.

As far as we can tell, all the known techniques of creativity can be implemented with larger or smaller adaptations, without restrictions (Mamede and Santos 2005).

The generated answers or solutions can be direct or indirect proposal solutions. A solution is considered to be direct when the answer possesses an immediate applicability for the resolution of the problem. On the other hand a solution is considered as indirect when the answer cannot be applied immediately but has potential to lead to the appearance of a direct solution. The degree of sophistication of the system can be measured by the number of supplied answers that can be considered more or less direct.

\section{The Architecture of a CIS}

The architecture for a creative information system that we consider in this section is based on a technique from Michael Michalko named brute thinking. This simple 
technique is based on a very simplified process, which is developed in four steps, as follows:

- Step 1 - Choose randomly a word

- Step 2 - Choose things/elements associated with the random word obtained

- Step 3 - Force links between the word and the problem and also between the associations and the problem

- Step 4 - List the obtained ideas and analyze them.

The construction strategy of a CIS based on this technique goes through the conception of an automatic system, assisted by a certain number of tools able to generate a set of phrases that can lead, after being analyzed by a user, to the creation of a new idea. In figure 2 there's a representation of such a global architecture.

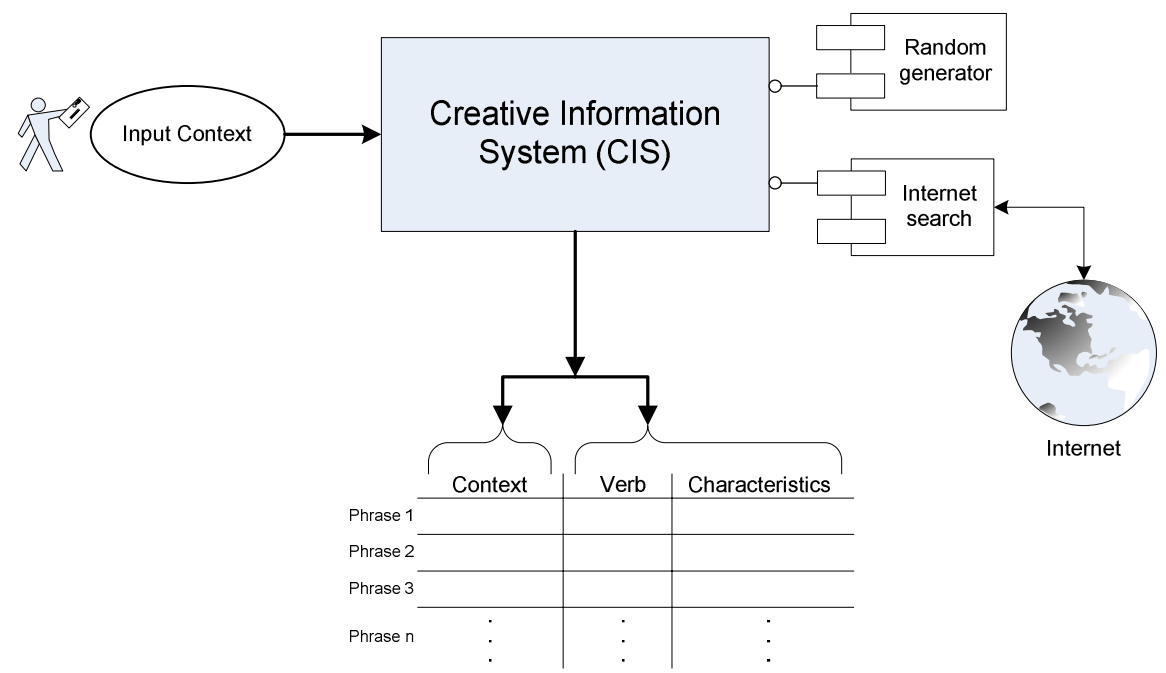

Fig. 2. Global architecture of a creativity information system based in brute thinking

In order for this to become possible, a context is supplied to the system by the user. This context will be used later, in the final phase of the sentences composition, attempting to generate a new idea based on the user's context. Simultaneously, a set of words representing tangible or intangible objects are generated, in a perfectly random form. For each one of these objects a set of key characteristics associated with it is determined. For this task of determination, a dictionary of characteristics from the Internet can be used.

After obtaining all those elements, the system should be able to generate phrases with a predetermined structure. Then, they are constituted by context - the verb, that will be also be randomly generated, and one of the predetermined key characteristics. The sentences will be generated and presented to the user for analysis; we estimate that only a very small percentage may have some meaning for the user. However, this will be the result of the exclusively random combinations, without any base in other previously existing ideas which could restrict the generator. 


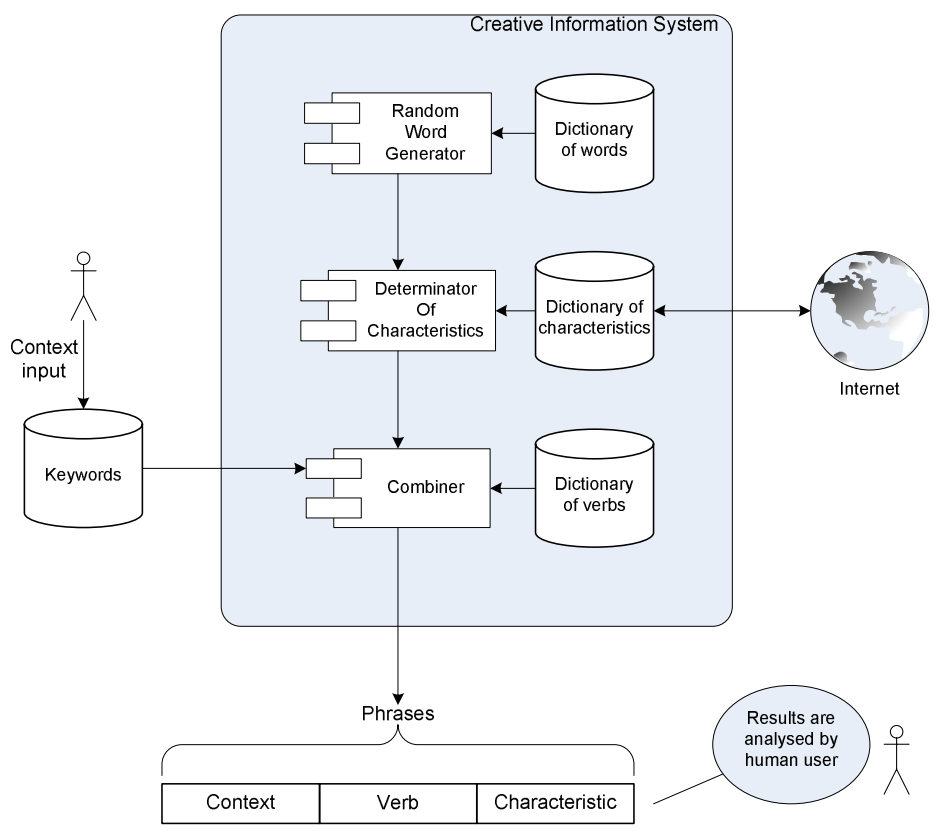

Fig. 3. Detailed architecture of a CSI

It is now possible to determine which of the elements shall constitute the central core of our creative information system needed to implement this architecture. We will need a random generator of words, an element capable of determining the characteristics of a given object and a module with the capacity to combine all of these elements with the keywords that describe the context generating phrases.

In this document, the element that comprises the architecture proposal is represented in figure 3 . The central element of the system architecture is a module capable of combining the objects and its characteristics with words, which describe the context where the generation of new ideas is demanded and the verb, giving origin to a phrase that might or might not constitute a new idea. To determine the use of the characteristics, the system carries out the creation of objects, based on a dictionary. For each one of these objects there are some characteristics which are common to all, supported or based on a dictionary, which searches it in the Internet and stores it for later reference. These are transferred into the combiner that conjugates them with the keywords, which describe the context of the user, and with a verb which is taken in turn from a proper dictionary. With the capacity to combine these elements, a set of phrases is generated and then analyzed by the user who will collect those that are effectively representing a new idea or proposal and will discard the rest.

\section{Conclusion and Future Work}

It becomes possible to use an information system that supports most automatic functions of the creative process by implementing different techniques. The final part 
requires it to be processed by a human user to determine, among the generated solutions, those that effectively can be used as solutions for the problem.

In the future, we will point out the effective development of a system that implements the architecture hereby proposed. Moreover, different architectures can be defined, with direct links to the different techniques of creativity that were mentioned in the beginning of this article. Sophistication levels can be developed, consisting of more elaborated techniques or using simultaneously several techniques for the creation of solutions or chances. The manner in which the creative techniques will be algorithmically implemented will also have a direct impact on the sophistication and quality of the answers which will be generated by the system. The possibility of creative information systems development is also possible on the basis of new ideas that can appear with this proposal.

\section{References}

Adams, J.L.: Guía y juegos para superar bloqueos mentales, 2nd edn. Editorial Gedisa, Barcelona (1986)

Arieti, S.: La creatividad, La síntesis mágica. Fondo de Cultura Económica, México (1993)

Baxter, M.: Projeto de produto: Guia prático para o design de novos produtos, 2nd edn. Editora Edgard Blücher, S. Paulo (2000)

Bennetti, P.: O Uso de Técnicas do Pensamento Criativo Facilita a Participação e o Comprometimento do Corpo Gerencial de uma Empresa com o Planeamento Estratégico. Tese de Mestrado em Criatividade Aplicada Total, Universidade de Santiago de Compostela (1999)

Binnig, G.: Aus dem Nichts: Über die Kreativität von Natur und Mensch. Piper Verlag, München (1997)

Bono, E.: De Bono's Thinking Course. BBC Books, London (1994)

Cardoso de Sousa, F.: A criatividade como disciplina científica. Colecção de Monografias Master de Creatividad, Servicio de Publicacións da Universidade de Santiago de Compostela, Santiago (1998)

Cross, N., Dorst, K., Roozenburg, N. (eds.): Research in Design Thinking. Delft University Press, Delft (1992)

Ferreras, A.P.: El cerebro creador. Psicologia, Alianza Editorial, Madrid (1999)

Gardner, H.: Mentes Creativas, una anatomía de la creatividad. Paidós, Barcelona (1998)

Gogatz, A., Mondejar, R.: Business Creativity - Breaking the Invisible Barrier. Palgrave Macmillan, New York (2005)

Gryskiewicz, S.: Discovering Creativity. Center Creative Leadership Press, USA (1993)

Guilford, J.P.: Creative talents: their nature, uses and development. Bearly Limited, Buffalo (1986)

Higgins, J.M.: Innovate or evaporate: Creative techniques for strategists. Long Range Planning Journal 29(3), 370-380 (1996)

Hudson, K.: The Idea Generator - Tools For Business Growth. Allen \& Unwin, Crows Nest (2007)

Jay, R.: The Ultimate Book of Business Creativity. Capstone Publishing Limited, Oxford (2000)

Jonas, W.: Design -System - Theorie, Überlegungen zu einem systemtheoretischen Modell von

Design-Theorie. Ed. Die Blaue Eule, Essen (1994)

Kao, J.: Jamming. HarperBusiness, New York (1996) 
Koestler, A.: The act of creation. Arkana Penguin Books, London (1964)

Mamede, H.S., Santos, V.: Uma Arquitectura para um Sistema de Informação Criativo. $6^{\text {a }}$ Conferência da Associação Portuguesa de Sistemas de Informação, Bragança, Portugal (2005)

Michalko, M.: Thinkertoys: A Handbook of Business Creativity For the 90s. Ten Speed Press, USA (1991)

Michalko, M.: Los secretos de los genios de la creatividad. Ed. Gestión, Barcelona (2000)

Mukerjea, D.: Brain Symphony. The Brainware Press, Singapore (2003)

Santos, V., Mamede, H.S.: Um Sistema de Informação Criativo baseado na técnica de criatividade whiteboard. In: Actas da $1^{\text {a }}$ CISTI (Conferência Ibérica de Sistemas e Tecnologias de Informação), Esposende, Portugal (2006)

Santos, V., Mamede, H.S.: Creative Information Systems. In: Freire, M., Pereira, M. (eds.) Encyclopedia of Internet Technologies and Applications, IGI Global, USA (2007)

Smith, F.: Pensar, Epigénese e Desenvolvimento. Instituto Piaget, Lisboa (1990)

Van Gundy, A.B.: Getting to Innovation: How Asking the Right Questions Generates the Great Ideas Your Company Needs. AMACOM, Boston (2007)

Wiener, N.: The Human Use of Human Beings: Cybernetics and Society. Houghton Mifflin Company, Boston (1950) 